\title{
PROFESSIONAL COMPETENCIES REQUIRED FOR PRINCIPALS OF BASIC EDUCATION SCHOOLS IN DHOFAR GOVERNORATE
}

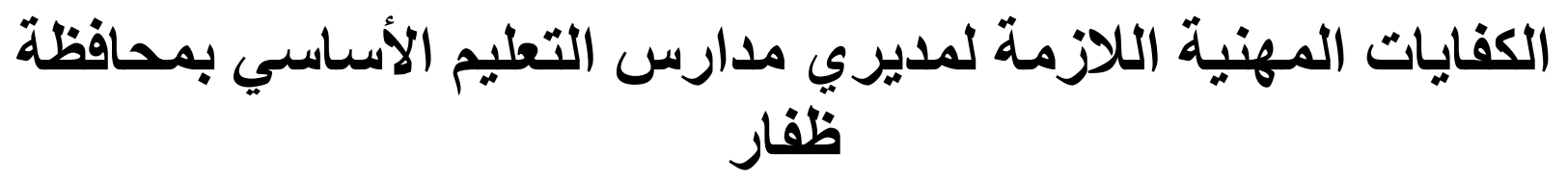

\author{
أحمد بن سهيل سالم العامري \\ Aamri Ahmed Suhail Salim ${ }^{1 *}$ and Muhammad Sabri Bin Sahrir ${ }^{2}$ \\ ${ }^{1}$ Ph.D. Candidate in Education at International Islamic University Malaysia, \\ ahmed103120@moe.om \\ ${ }^{2}$ Assoc. Prof. Dr. in Education at at International Islamic University Malaysia, \\ muhdsabri@iium.edu.my \\ ${ }^{*}$ Corresponding Author
}

\begin{abstract}
This quantitative study discussed the professional competencies required for principals of basic education in Dhofar Governorate. The problem lies in the lack of training programs, and the need to enhance the knowledge, value, and skills dimensions. The study objective: was to determine the necessary professional competencies for principals of basic education schools in Dhofar Governorate. The researcher adopted the descriptive and analytical approach and a random sample of (75) principals were selected for basic education. The researcher designed a questionnaire to collect data, consisting of (46) statements distributed in three axes. The results of the study showed that social competencies came in first place with very high esteem, followed by educational competencies, while scientific competencies came third with high esteem.
\end{abstract}

Keywords: professional competencies, school principals, basic education.

$$
\text { الملخص }
$$

ناقثت هذه الدر اسة الكمية الكفايات المهنية اللازمة لمدر اء التعليم الأساس بمحافظة ظفار ، وتكمن المشكلة في وجود نقص في البرامج التدريبية، والحاجة إلى تعزيز الأبعاد المعرفية والقيمية و المهار اتية. هدفتن الدراسة؛ تحديد الكفايات المهنية اللازمة لمديري مدارس التعليم الأساسي فئي

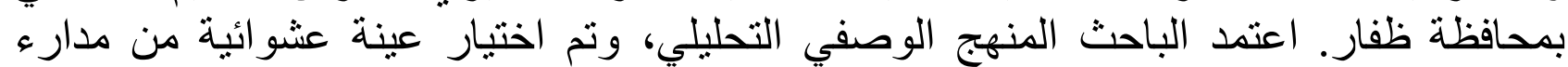
التعليم الأساسي قدر ها (75) مدير ا ومديرة. صمم الباحثة استبانة لجمع البيانات، تكونت من فئ (46)

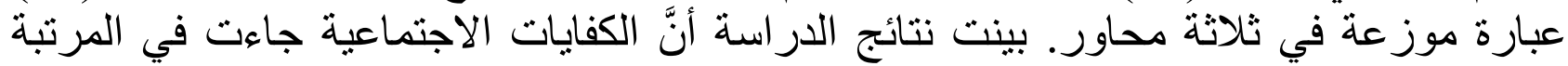
الأولى وبتقدير عال جدا، تلتها الكفايات التربوبة، في حين حلتُ الكفايات العلمبة ثالثا وبتقدير عالٍٍ. 
الكلمات المفتاحية: الكفايات المهنية، مدر اء المدارس، التعليم الأساس.

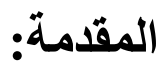

إن الدور الذي يقوم به مدير المدرسة لتحقيق الوظائف الأساسية متمثلة في رعاية التلاميذ و الحفاظ

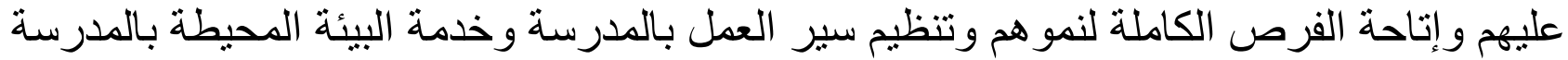

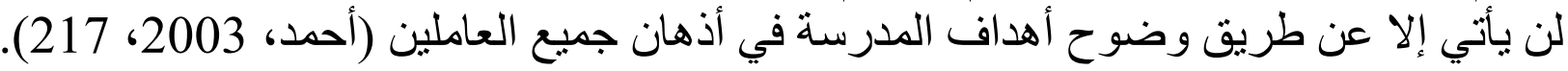

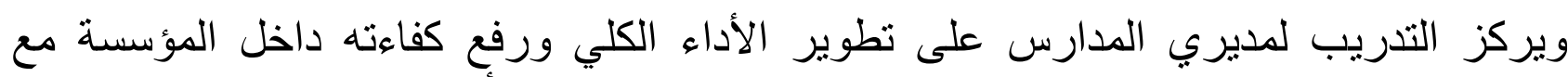

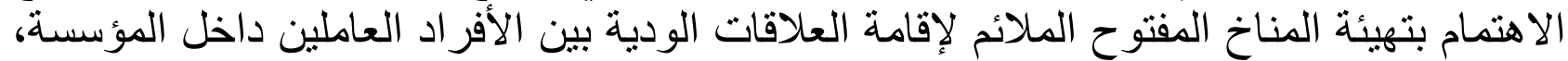

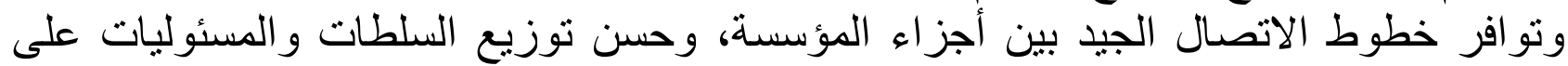

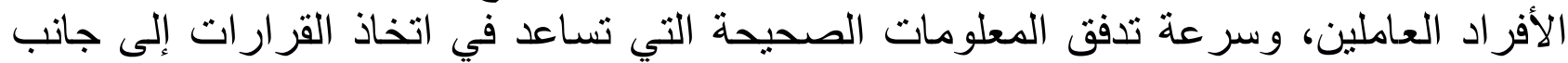

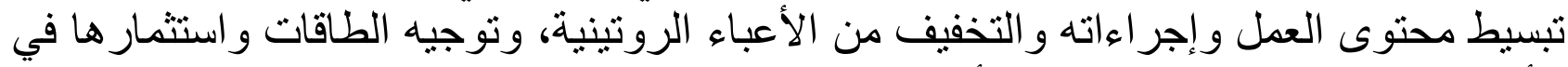

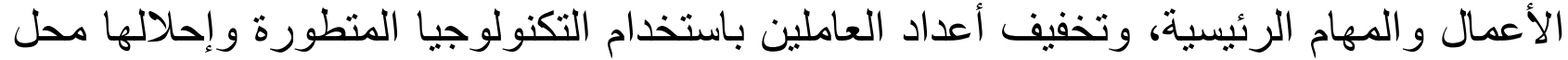

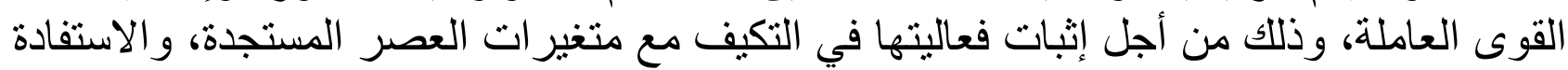
منها في سبيل تحقيق الأهداف الحالية و المستقبلية للمؤسئات التئي التي تقوم بإدارتها (الحربي، 2009،

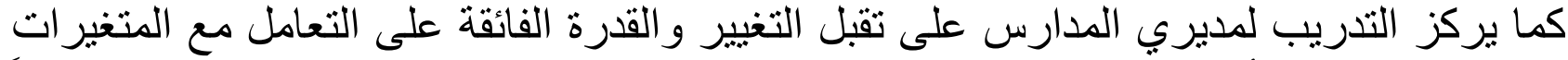

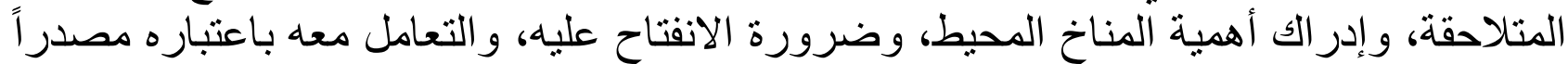

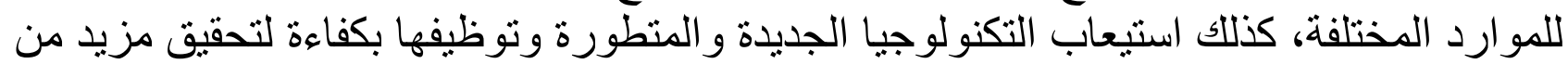

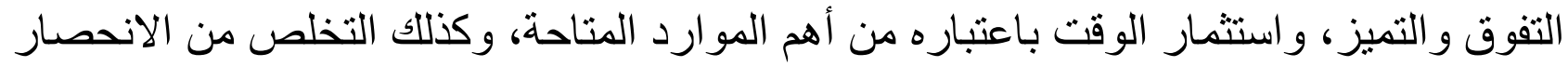

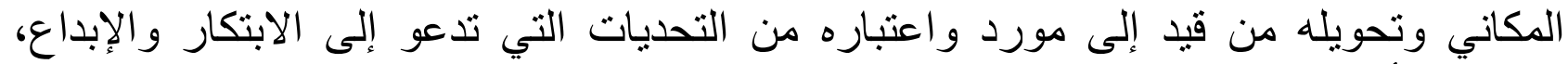

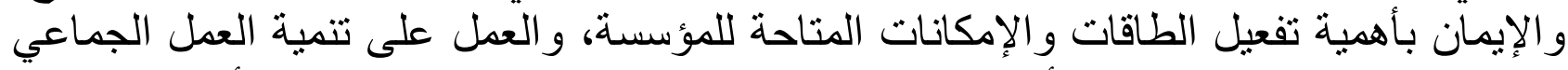

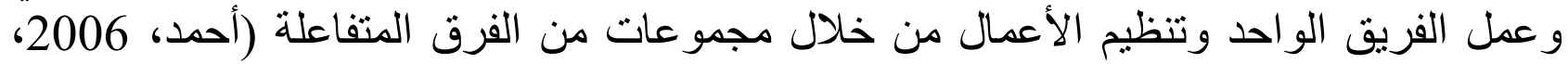

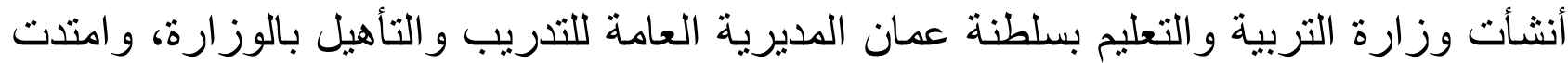

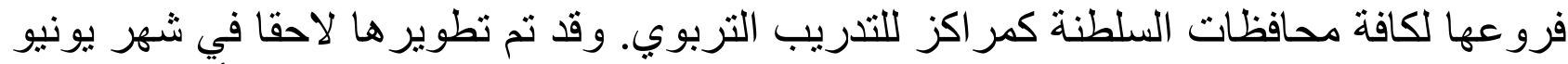

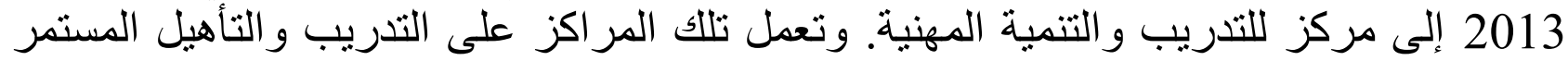

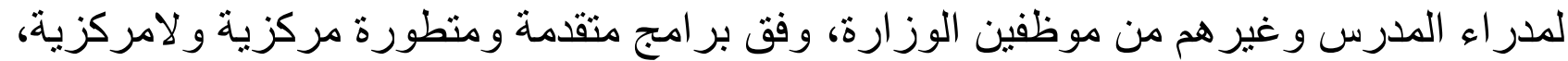

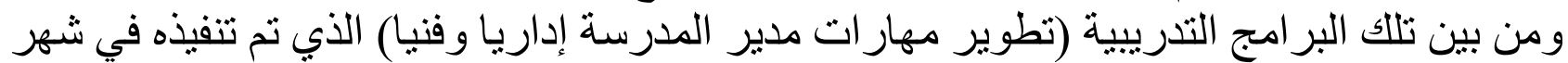

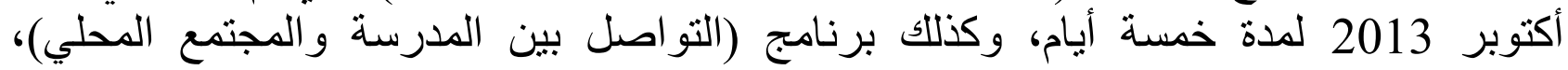

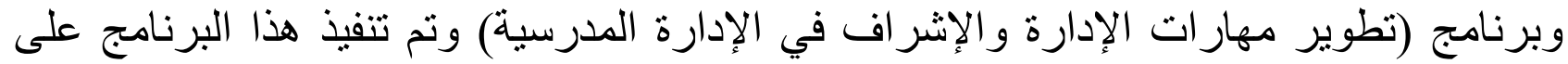

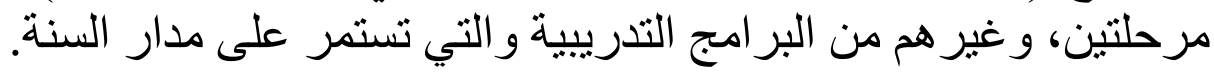

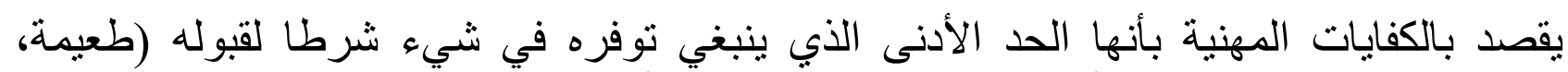

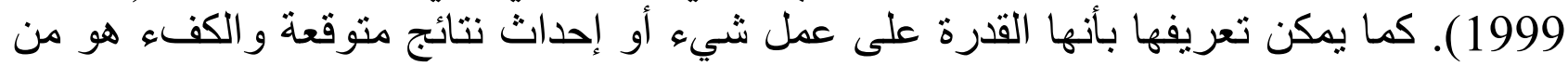

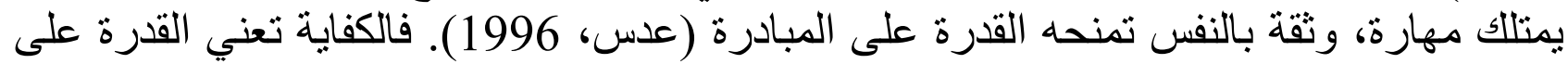

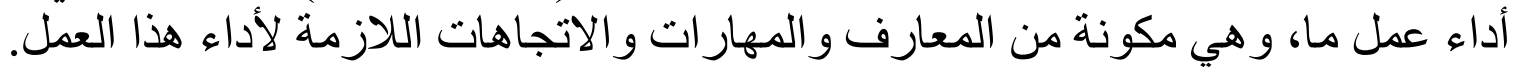




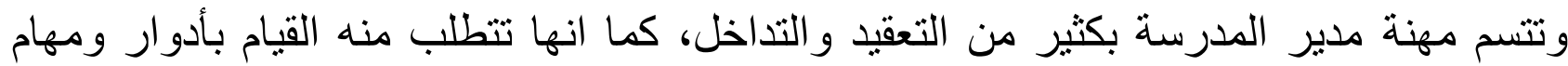

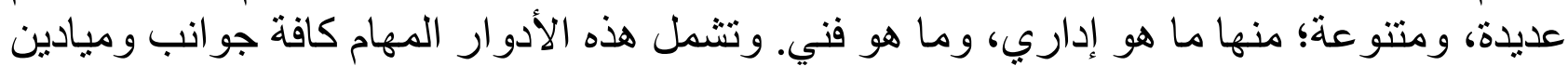

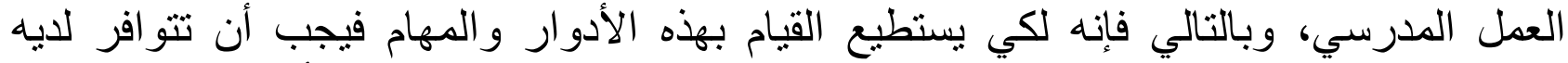

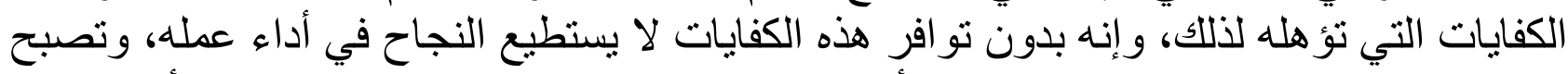

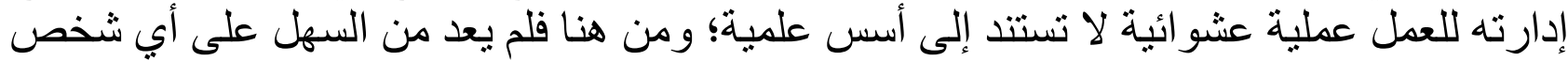

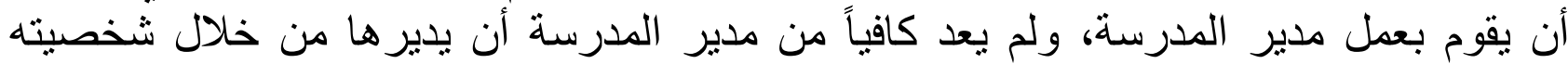

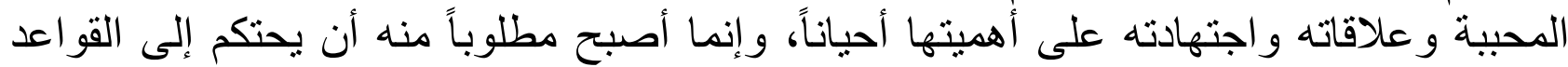

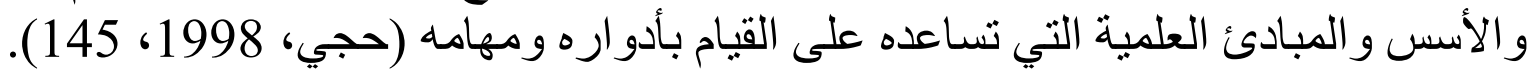

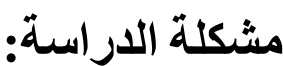

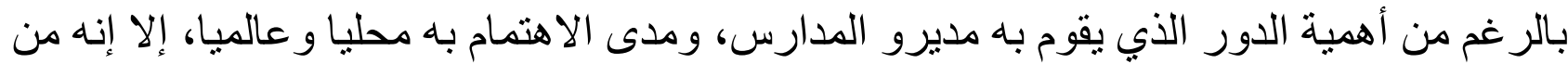

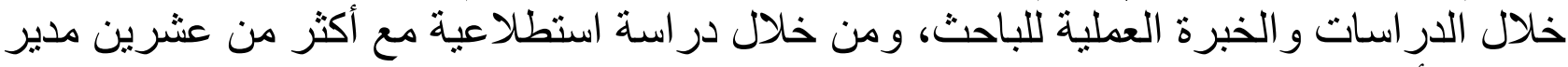
مدرسة، أتضح للباحث ما يلي:

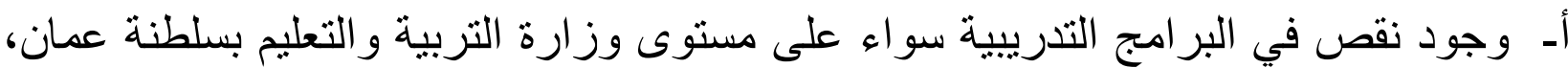

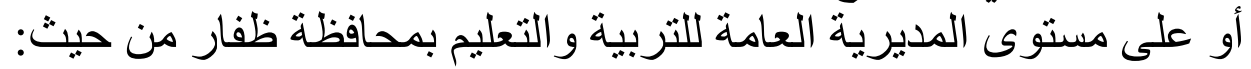
- البعد المعرفي للمديرين: ويتعلق بيناء قاعدة معرفية ومفاهيمية عميقة لدى المديرين تمكنهم من التفاعل مع المستجدات الإدارية الحديثة. - ـ البعد القيمي: لمساعدة مدر اء المدارس من الحكم على الأمور في ضوء معايير محددة في تكوين اتجاهاتهم. - البعد المهار اتي: وهو ترجمة إجرائية سلوكية للبعدين المعرفي والقيمي وتحويلها إلى التى

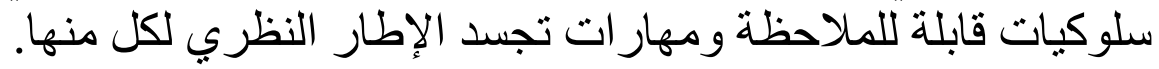

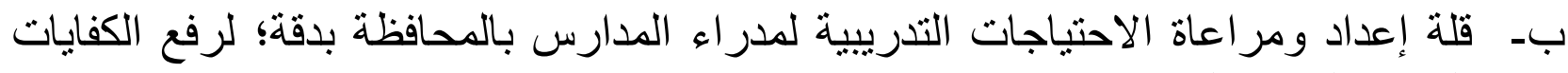

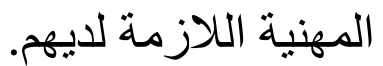

تــ ضرورة الوقوف على الكفايات المهنية اللازمة لمديري مدر اس التعليم الأساسي بمحافظة ظفار. مما دعى الباحث القيام بهذه الدراسة لأجل تنمية الكفايات المهنية لدى مديري مدرس التعليم الأساسي بالمحافظة. دافة الهُف الرئيس للاراسة: تحديد الكفايات المهنية اللازمة لمديري مدارس التعليم الأساسي بمحافظة ظفار.

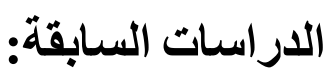
دراسة نورمان (2005, Norman):

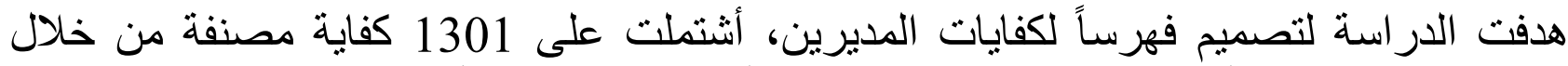

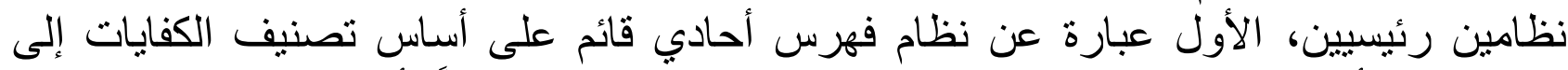

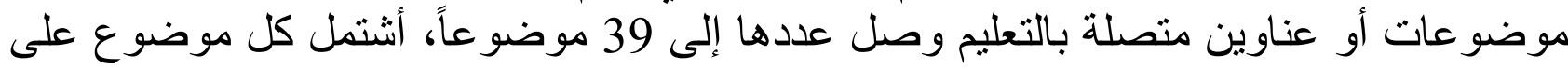




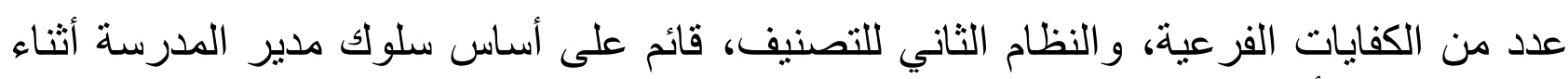

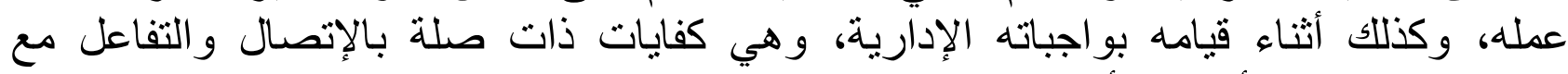

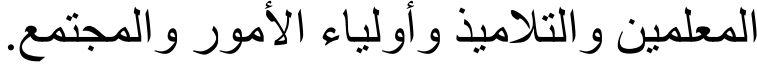

دراسة جونسون (Johnson 2006):

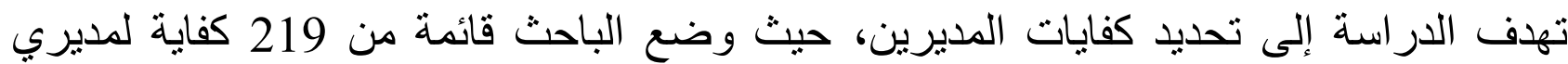

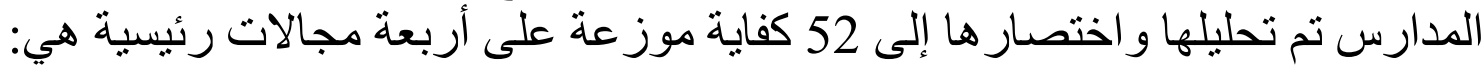

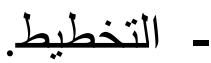
- م ت تشخيص حالات المتعلمين. ـ - الخصائص المهنية و الأخلاقية.

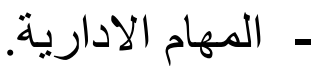

وقدتوصلت الدراسة إلى أنه يجب الاخذ بالاعتبار كل المجالات الرئيسة السابقة حتي تم تنمية

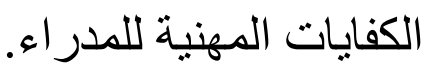
دراسة موسويلا (2006, Moswela): هدفت الدراسة إلى الكثف عن الاحتياجات التدريبية للمديرين أثناء الخدمة بغرض تحسين أداء

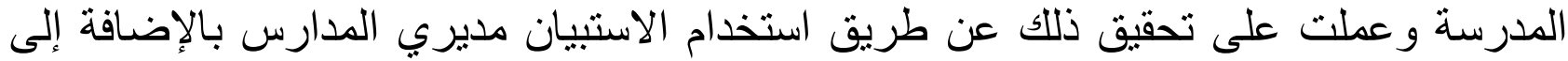

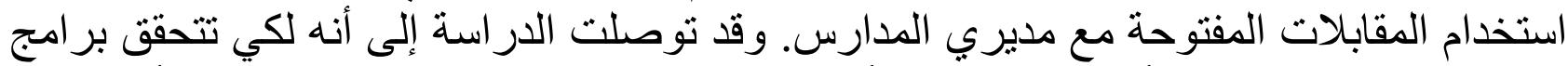

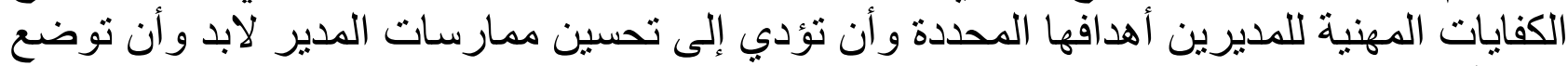

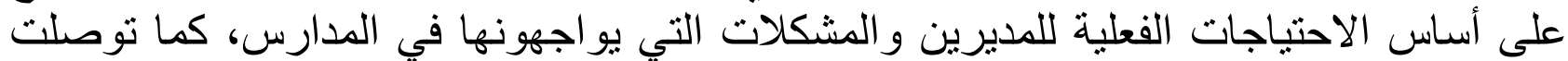

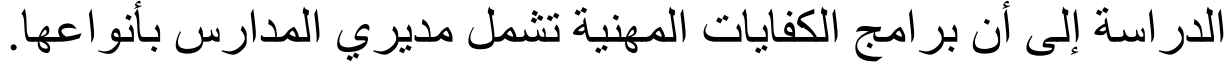

دراسة روبرت ( 2007, Robert)

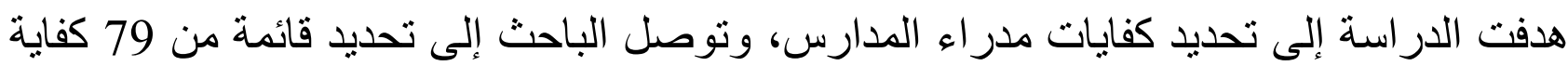

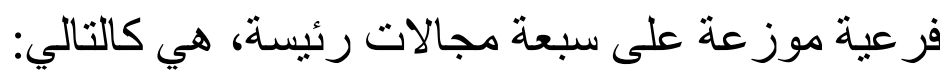

- متخيص وتحديد المهار ات.

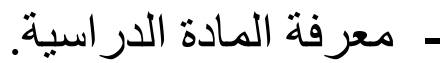
- - 2 - مهار ات تختص بالمناهج. - مهار ات تختص بالادارة المدرسية.

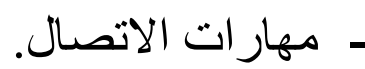

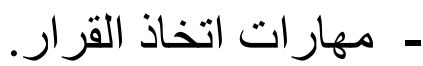

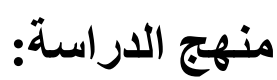

اعتمد الباحث فى هذه الدر اسة على المنهج الوصفي الذى يصف الظاهرة كما هى فى الو اقع ويعبر

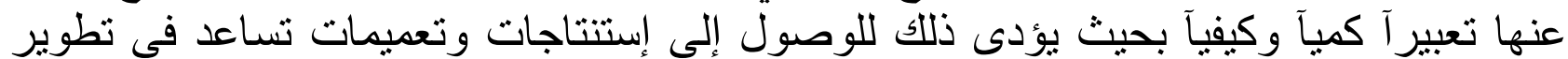


الو اقع المدروس.

مجتمع الدراسة: تكون مجتمع الدراسة من مديري ومديرات مدار مدارس التعليم الأساسي بمحافظة

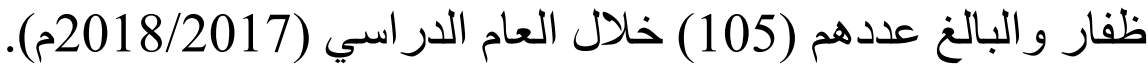

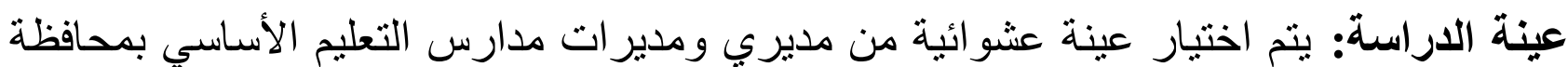

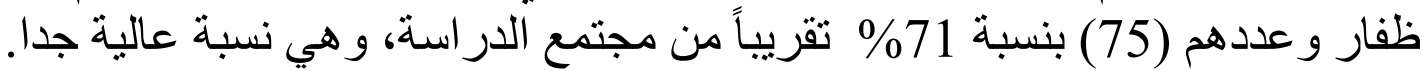

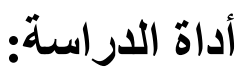
جرى تحليل أدوار ومسؤوليات مدير المدرسة للتعرف على الكفائل الكفايات المهنية اللازمة لها، و إعداد

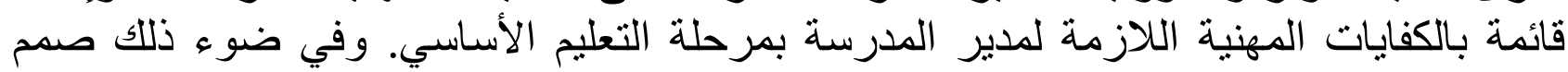

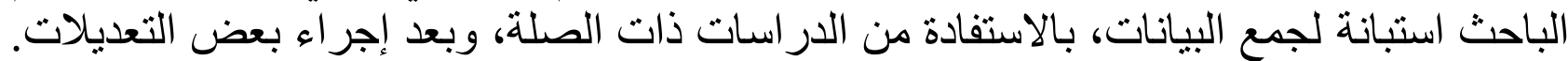

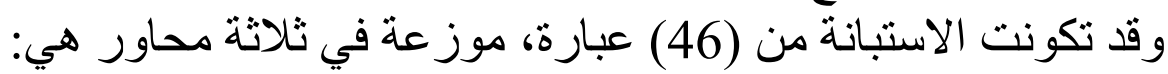

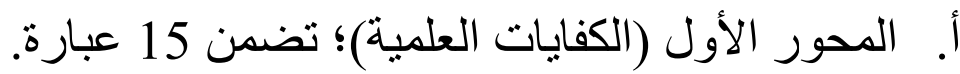

ب. المحور الثاني (الكفايات التربوية)؛ تضمن الكون 16 عبارة. ت. المحور الثالث (الكفايات الاجتماعية)؛ تضمن 15 عبارة.

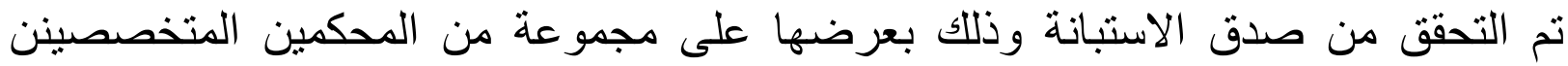

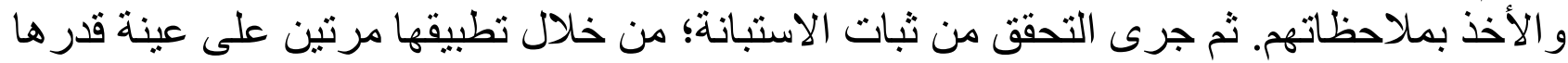

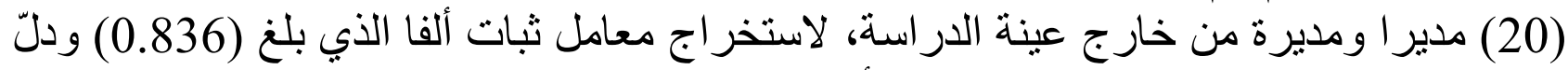
على صلاحية المقياس لاستخر اج ما ما صمد لأجله.

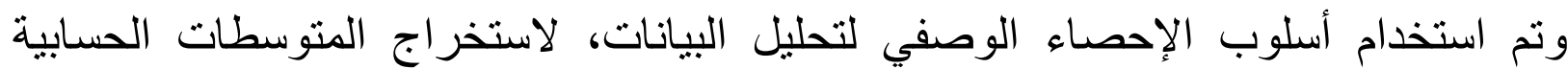

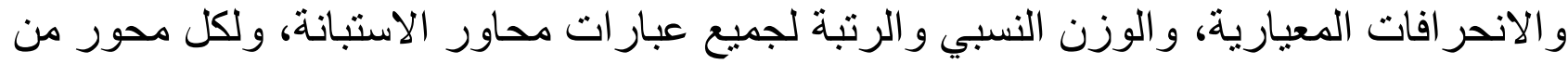

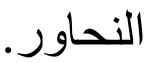

نتائج الاراسة: النتائج المتعلقة بالإجابة عن سؤال الدراسة: للإجابة عن السؤال الرئيس للار اسة الذي نص على لإبه: ما الكفايات المهنية اللازمة لمديري مدارس

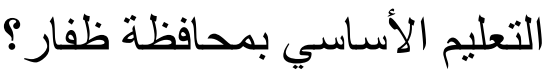
نتائج المحور الأول:

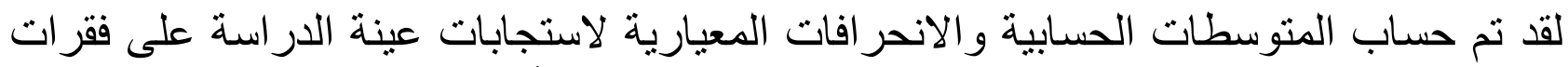

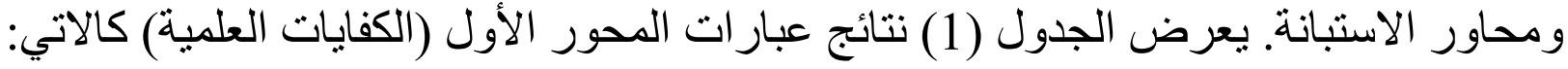
جدول (1) استجابات عينة الدر اسة على فقرات المحور الأول (الكفايات العلمية)

\begin{tabular}{|c|c|c|c|c|}
\hline 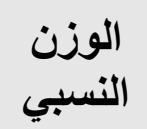 & المعياري & الحسابي & 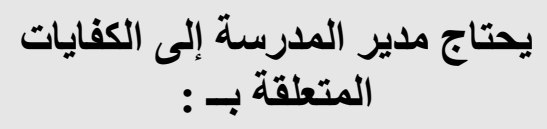 & الفقرة \\
\hline
\end{tabular}


IJASOS- International E-Journal of Advances in Social Sciences, Vol. VI, Issue 18, December 2020

\begin{tabular}{|c|c|c|c|c|c|}
\hline 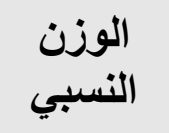 & الانمر افياري & المستوسط المبي & يحتاج مدير المدرسة إلى الكفايات & 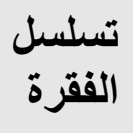 & 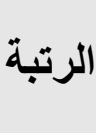 \\
\hline$\% 89,00$ & 0,69 & 4,45 & مهامهاب. معارف ومهار ات جديده حول & 6 & 1 \\
\hline$\% 89,00$ & 0,77 & 4,45 & استخدام التقنيات الإلكترونية الحديثة. & 4 & 2 \\
\hline$\% 87,80$ & 0,57 & 4,39 & المناستخد. استر اتيجيات اتخاذ القرار & 3 & 3 \\
\hline$\% 87,40$ & 0,7 & 4,37 & تمكن الادارة المدرسية. الطرائق العلمية الحديثة & 13 & 4 \\
\hline$\% 86,40$ & 0,73 & 4,32 & للقياس. التمكن من صياغة أهداف و اضحة وقابلة & 7 & 5 \\
\hline$\% 85,60$ & 0,81 & 4,28 & التربوية الحديثة لاكتشاب أساليب على الخبرة. الادارة & 2 & 6 \\
\hline$\% 85,40$ & 0,65 & 4,27 & واستخدامها اسس التوجيه التربوي و النفسي & 12 & 7 \\
\hline$\% 85,40$ & 0,74 & 4,27 & الاطلاع على تجارب سابقة والاستفادة & 11 & 8 \\
\hline$\% 85,00$ & 0,89 & 4,25 & الطارئة في ميدان التثل اتيجيات حلى الخلوب علافات & 5 & 9 \\
\hline$\% 82,20$ & 0,84 & 4,11 & تدريبية في المدرسةت مهارة تنفيذ مشاغل ودورات & 8 & 10 \\
\hline$\% 82,20$ & 0,87 & 4,11 & و عدم اللجوء استخاليب البحث العشو ائية. العلمي والتفكير & 10 & 11 \\
\hline$\% 78,00$ & 0,98 & 3,9 & الاعتماد على التقويم الالكتروني. & 15 & 12 \\
\hline$\% 76,80$ & 0,86 & 3,84 & في التناج الوسائل التعليمية. موارد البيئة المتاحة & 14 & 13 \\
\hline$\% 71,20$ & 0,97 & 3,56 & ذات التعلاونة العلمي مع المؤسئة المدرسة. و الثركات & 9 & 14 \\
\hline$\% 49,80$ & 1,25 & 2,49 & القيام بأبحاث علمية ونشر نتائجها. & 1 & 15 \\
\hline
\end{tabular}


IJASOS- International E-Journal of Advances in Social Sciences, Vol. VI, Issue 18, December 2020

\begin{tabular}{|c|c|c|c|c|c|}
\hline 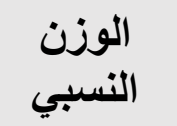 & الانحر افياري & المسابي المتوسط & يحتاج مدير المدرسة إلى الكفايات & ت الفقرة & 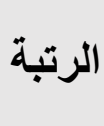 \\
\hline$\% 81,40$ & 0,82 & 4,07 & \multicolumn{3}{|c|}{ معدل عبارات المحور الأول } \\
\hline
\end{tabular}

من خلال الجدول السابق يتضح ما يلي: - المنوسط العام لارجة استجابات أفراد عينة الدراسة للمحور الأول (الكفايات العلمية) هو (4.07) وبوزن نسبي (191,40\%).

ـ ق قيمة المتوسطات الحسابية لهذا المحور تراوحت اونت ما بين (2.49-4.45)، وبأوزان نسبية تر اوحت بين (49,8\% - 899 ).

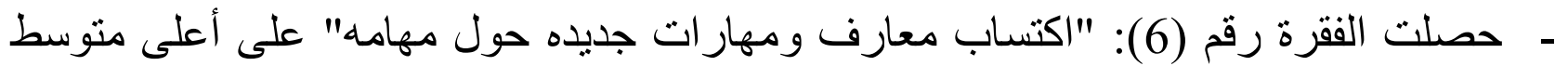

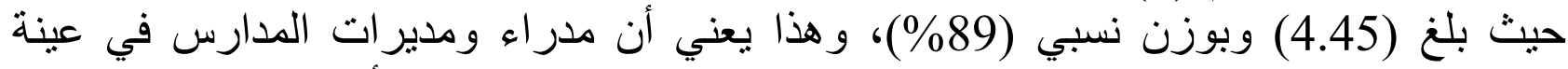

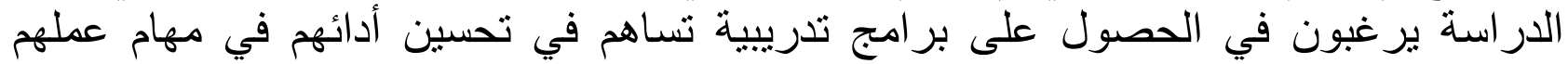

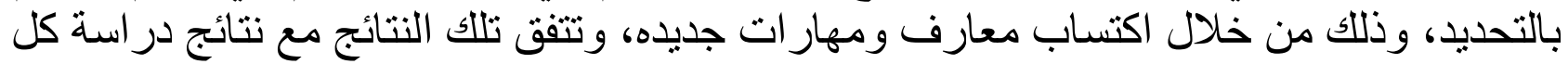

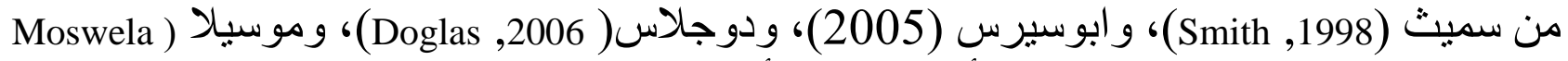

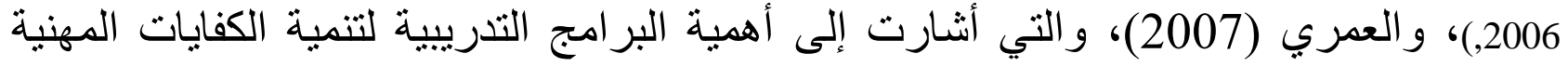

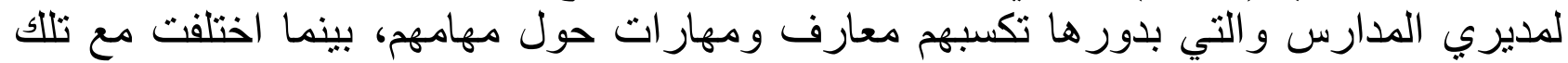

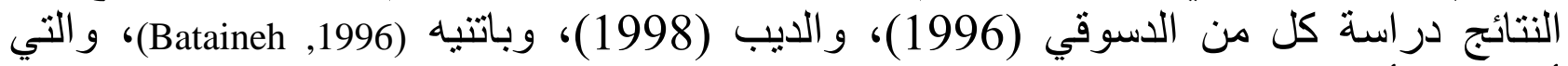

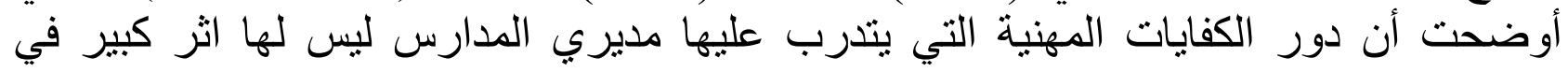
اكسابهم مهار ات ومعارف دور حول مهامهم.

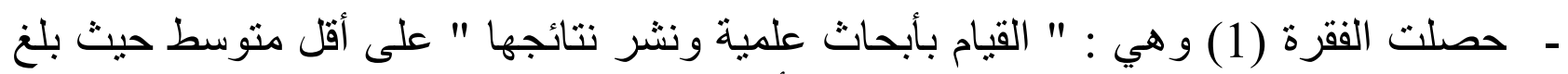

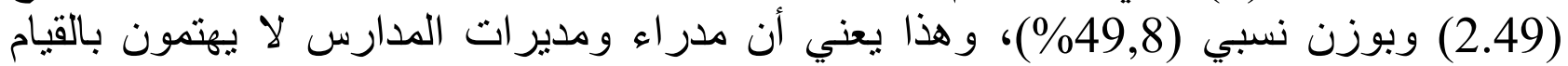

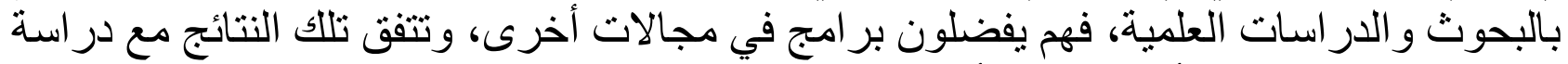

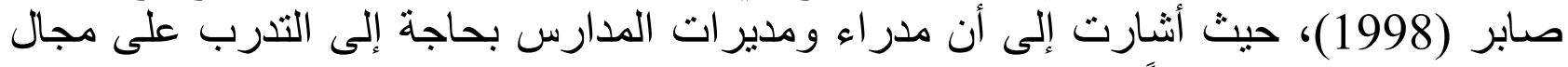
البحوث و الدر اسات، نظر اً لتدني خبرتهم في هذا المها المجال.

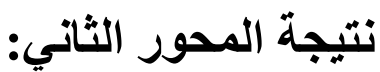

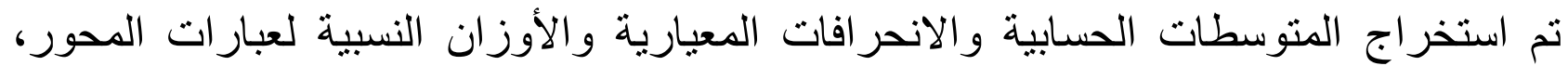
ويعرض الجدول (2) نتائج عبار ات المحور الثاني (الكفايات التربوية):

جدول (2) استجابات عينة الدراسة على فقرات المحور الثاني (الكفايات التربوية)

\begin{tabular}{|c|c|c|c|c|c|}
\hline 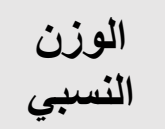 & 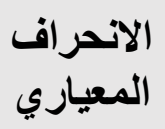 & المتوسط & يحتاج مدير المدرسة إلى الكفايات المتعلقة & 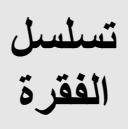 & الرتبة \\
\hline$\% 94,20$ & 0,51 & 4,71 & اثارة دافعية المعلمين لبذل الكثير من الجهد. & 10 & 1 \\
\hline
\end{tabular}




\begin{tabular}{|c|c|c|c|c|c|}
\hline 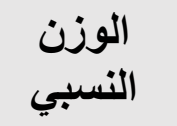 & الانحراف المعياري & المتوسط المبي & يحتاج مدير المدرسة إلى الكفايات المتعلقة & 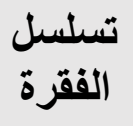 & 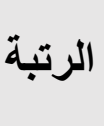 \\
\hline$\% 93,40$ & 0,53 & 4,67 & لايه مهار ات توظيف اساليب التعزيز & 9 & 2 \\
\hline$\% 92,00$ & 0,6 & 4,6 & كتب، وسائل تعليمية) الاحتيات المدرسية من(معمين، & 3 & 3 \\
\hline$\% 91,20$ & 0,61 & 4,56 & في المدرسة. في توفير كافة احتياجات المعلمين & 7 & 4 \\
\hline$\% 91,00$ & 0,56 & 4,55 & و الشخرص الظو اهر السلبية في سلوك الطلاب & 12 & 5 \\
\hline$\% 89,20$ & 0,53 & 4,46 & التخطيط الفعال وفق ضو ابط محددة. & 1 & 6 \\
\hline$\% 89,20$ & 0,56 & 4,46 & تحديد الاهداف التعليمية في مختلف جو انبها & 2 & 7 \\
\hline$\% 89,20$ & 0,77 & 4,46 & تحصليلياً. خطط علاجية للطلاب المتدنيين & 5 & 8 \\
\hline$\% 89,20$ & 0,58 & 4,46 & در اعاة الفروق الفردية في اداء المعلمين & 13 & 9 \\
\hline$\% 88,80$ & 0,61 & 4,44 & توفير بيئة تعليمية مشجعة للتعليم و التعلم & 8 & 10 \\
\hline$\% 88,00$ & 0,67 & 4,4 & استخدام اساليب التقويم المختلفة. & 6 & 11 \\
\hline$\% 88,00$ & 0,67 & 4,4 & توجيه عمليتي التعليم والتعلم نحو خدمة & 11 & 12 \\
\hline$\% 84,80$ & 0,77 & 4,24 & تشجيع المعلمين على البحث و الاطلاع & 15 & 13 \\
\hline$\% 83,40$ & 0,8 & 4,17 & و تقويم النفوقين. و وبر امج مختلفة للموهوبين & 4 & 14 \\
\hline$\% 82,80$ & 0,79 & 4,14 & تلمعليد برامج تتموية تحقق التطور الذاتي & 14 & 15 \\
\hline$\% 79,20$ & 0,81 & 3,96 & الذاتي للمعلمين. برجق المزيد من فرص التقويم & 16 & 16 \\
\hline$\% 88,40$ & 0,65 & 4,42 & معدل عبارات المحور الثاني & & \\
\hline
\end{tabular}


من خلال الجدول السابق يتضح ما يلي: - - المتوسط العام لدرجة استجابات أفر اد عينة الدراسة للمحور الثاني (الكفايات التربوية) هو (4.42) وبوزن نسبي (1\%,40).

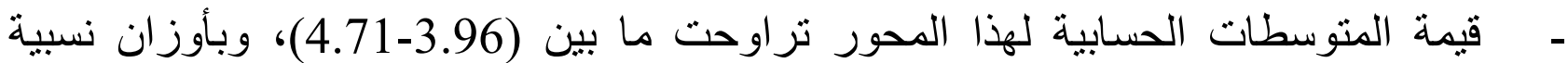
تراوحت بين (2\%,2\% - 94,2\%).

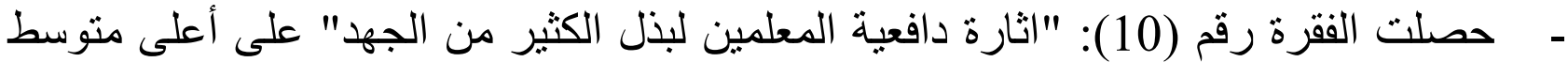

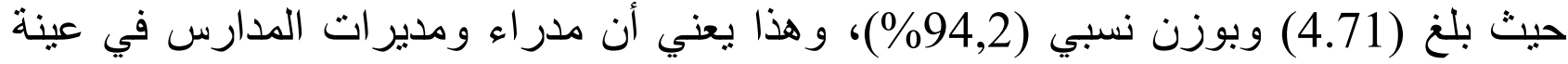

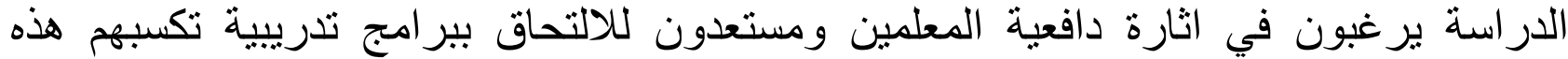

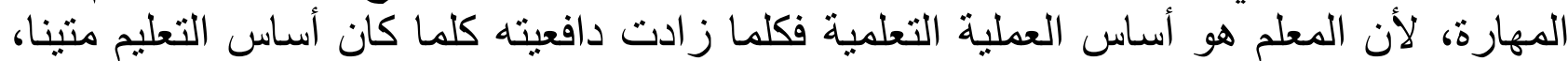

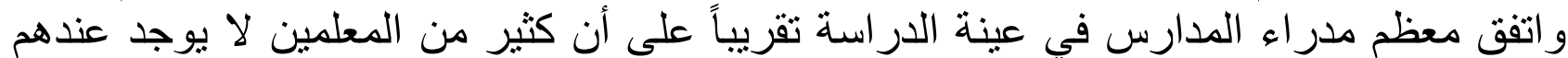

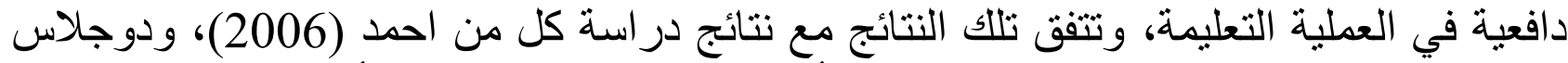

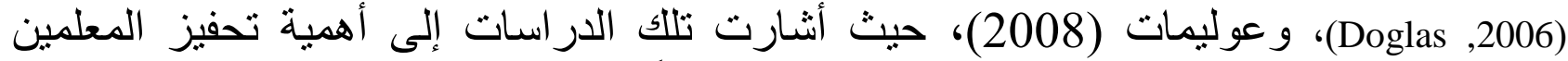

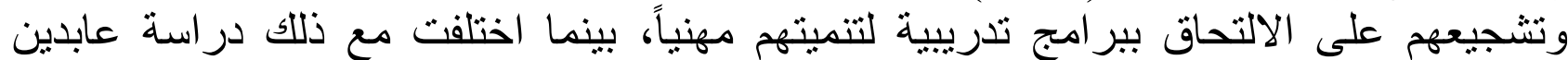

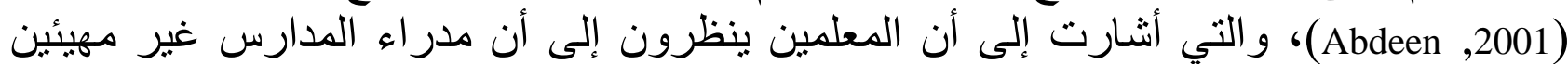
جيداً، و انهم ينظرون للمعلمين بتعالي.

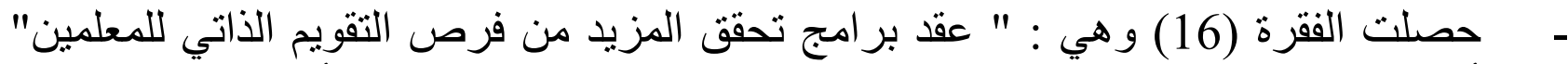

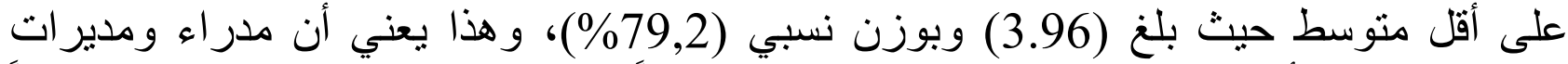

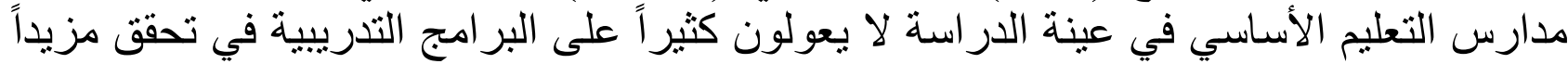

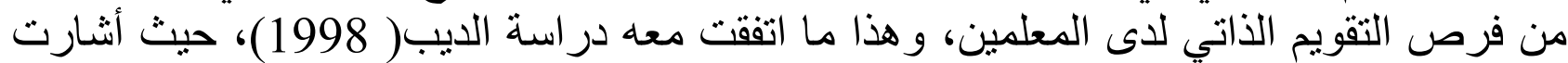

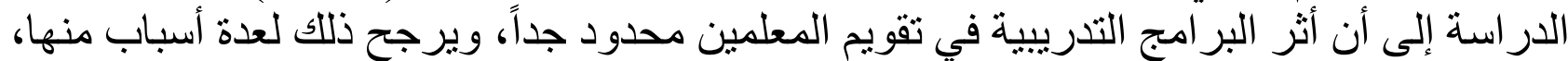

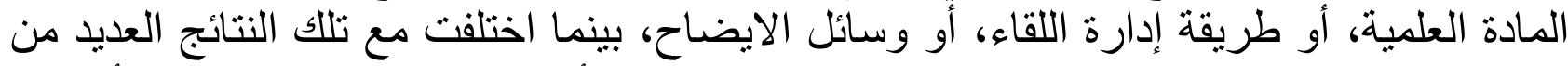

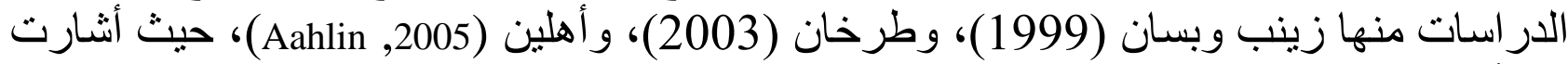
إلى أهمية البر امج التدرييية في رفع كفاءة المتدرب في كافة المجالات ومنها التقويم الذاتي.

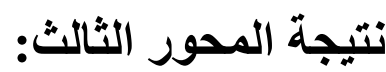

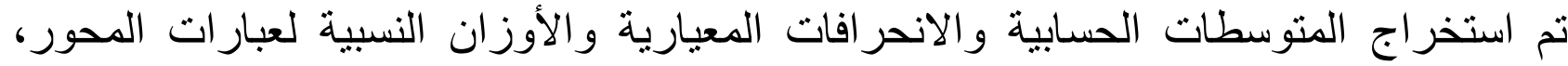

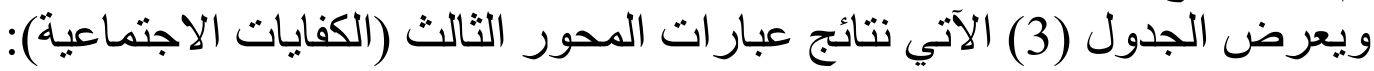
جدول (3) استجابات عينة الدر اسة على فقرات المحور الثالث (الكفايات الاجتماعية)

\begin{tabular}{|c|c|c|c|c|c|}
\hline 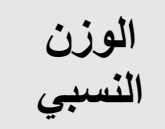 & 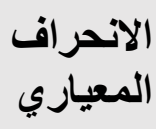 & المتوسط & يحتاج مدير المدرسة إلى الكفايات المتعلقة بـ: & 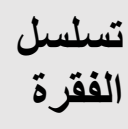 & الرتبة \\
\hline$\% 95,80$ & 0,51 & 4,79 & غرس القيم و الاخلاق الفاضلة في المدرسة. & 4 & 1 \\
\hline$\% 95,00$ & 0,43 & 4,75 & المدرسية. على العمل في فريق واحد متعاون داخل & 15 & 2 \\
\hline
\end{tabular}




\begin{tabular}{|c|c|c|c|c|c|}
\hline 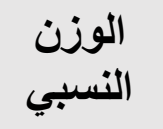 & المعياري & المتوسط & يحتاج مدير المدرسة إلى الكفايات المتعلقة بـ: & 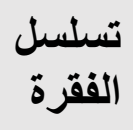 & 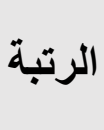 \\
\hline$\% 94,80$ & 0,44 & 4,74 & خلق جو من الاطمئنان داخل المدرسة. & 10 & 3 \\
\hline$\% 93,40$ & 0,47 & 4,67 & والتعادل مع اعداد كبيرة من الطلاب والمعلمين & 3 & 4 \\
\hline$\% 92,80$ & 0,48 & 4,64 & المدرسة. روح التعاون في الفريق الذي يقوده داخل & 9 & 5 \\
\hline$\% 91,40$ & 0,58 & 4,57 & تكوين اتجاه ايجابي نحو مهنة التعليم. & 2 & 6 \\
\hline$\% 91,40$ & 0,53 & 4,57 & الحرص على تقدير وجهات النظر و الارتقاء بها. & 14 & 7 \\
\hline$\% 90,80$ & 0,61 & 4,54 & الاداريين) علاقات ايجابية مع ( الطلاب, المعلمين, & 7 & 8 \\
\hline$\% 90,80$ & 0,5 & 4,54 & والفخر بهاهة في ايجاد احساس بقيمة ما بنجزه الفرد & 13 & 9 \\
\hline$\% 89,80$ & 0,53 & 4,49 & القدرة على حل المشكلات الادارية والتعليمية. & 8 & 10 \\
\hline$\% 89,40$ & 0,56 & 4,47 & و الربطيق بينه. نواحي العمل وبين مصلحة المدرسة & 12 & 11 \\
\hline$\% 88,60$ & 0,6 & 4,43 & والوعي بمشكية الادارية. & 1 & 12 \\
\hline$\% 88,20$ & 0,6 & 4,41 & التعليمية. مساعدة الطلاب للتعبير عن افكار هم في المواقف & 5 & 13 \\
\hline$\% 87,00$ & 0,56 & 4,35 & تفعيل بر امج تحفيزية للعاملين. & 11 & 14 \\
\hline$\% 84,80$ & 0,58 & 4,24 & الطعاون ملع مشكلاتهم. الأمور لتحسين مستوى & 6 & 15 \\
\hline$\% 91$ & 0,53 & 4,55 & معدل عبارات المحور الثالث & & \\
\hline
\end{tabular}

من خلال الجدول السابق يتضح ما يلي: ـ المتوسط العام لدرجة استجابات أفر اد عينة الدراسة للمحور الثالث (الكفايات الاجتماعية) هو (4.55) وبوزن نسبي (191\%). 


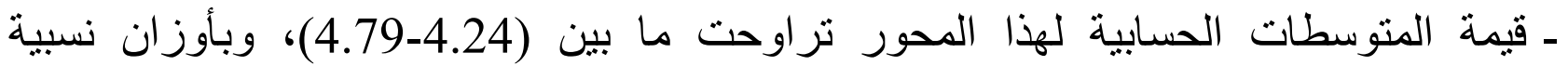

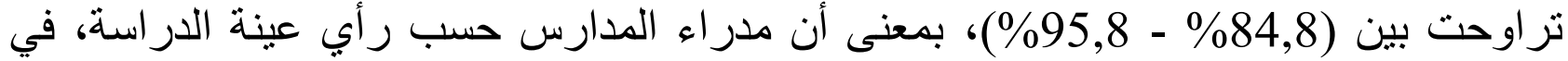

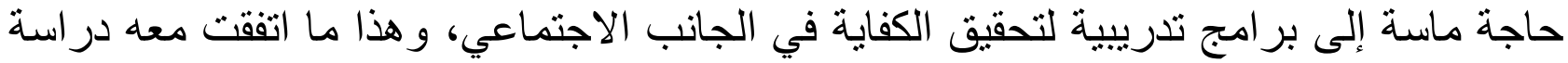

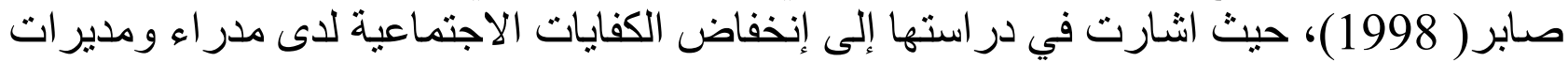
المدارس مما يتطلب بر امج تدرييية على الكفايات الاجتماعية.

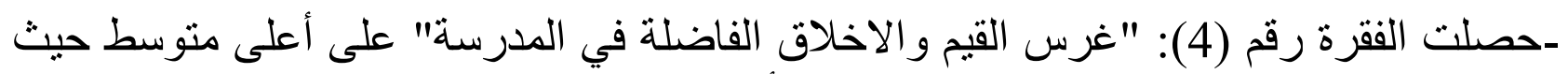

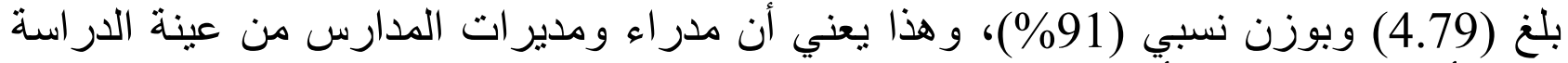
يرون أن غرس القيم و الأخلاق الفاضلة في المدرسة من الكفاء أن مدات التي يحتاجونها بشدة.

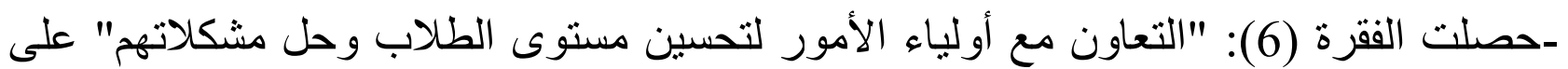

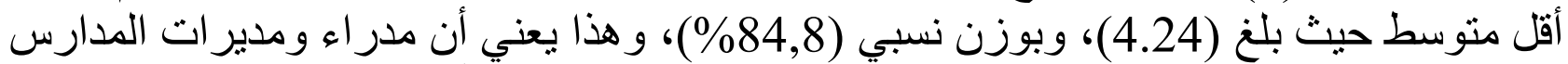

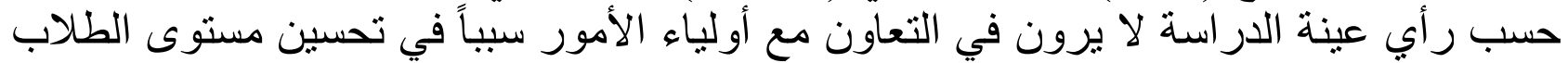

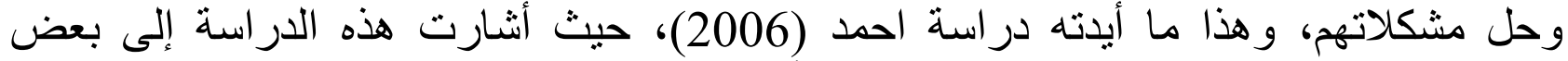

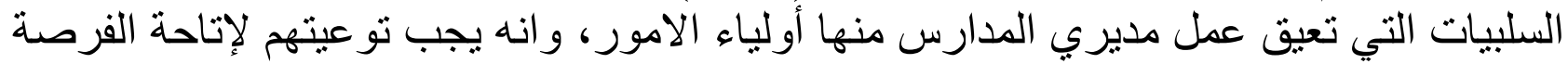

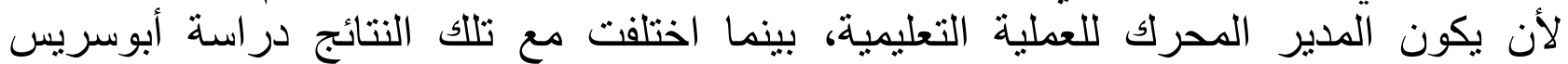

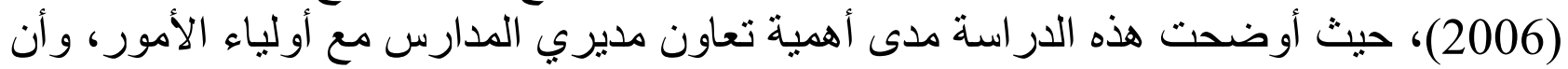
ذللك قد يؤدي لتحسين مستو اهم التعليمي. الجدول الآتي يبين استجابات العينة على جميع محاور الاستبانة: جدول (4) استجابات عينة الدر اسة على جميع محاور الاستبانة

\begin{tabular}{|c|c|c|c|c|}
\hline النسبي & المعياري & الحستبي & المحور & ت \\
\hline$\% 81,40$ & 0,82 & 4,07 & الكفايات العلمية & 1 \\
\hline$\% 88,40$ & 0,65 & 4,42 & الكفايات التربوية & 2 \\
\hline$\% 91,00$ & 0,53 & 4,55 & الكفايات الاجتماعية & 3 \\
\hline$\% 87$ & 0,67 & 4,35 & المعدل العام لمحاور الاستبانة & \\
\hline
\end{tabular}

من خلال الجدول السابق يتضح ما يلي:

ـ ـ المتوسط العام لدرجة استجابات أفراد عينة الدراسة على جميع محاور الاستبانة هو (4.35) وبوزن نسبي (87\%).

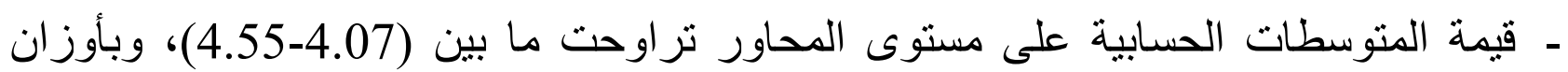
نسبية تر اوحت بين (88,4\% - 91\%). - حصل المحور الثالث (الكفايات الاجتماعية) على أعلى متوسط حيث بلغ (4.55) وبوزن 


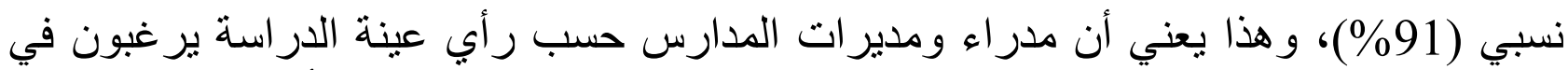

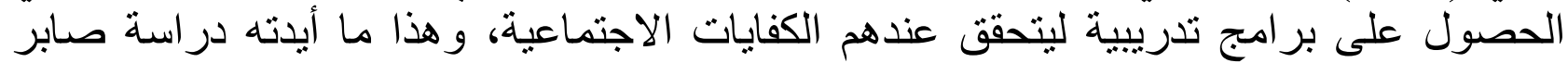

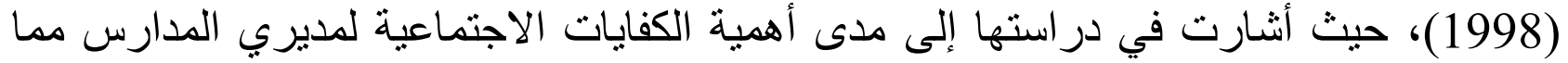
يتطلب بر امج تدريبية عليها.

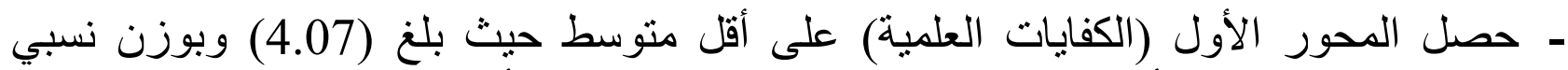

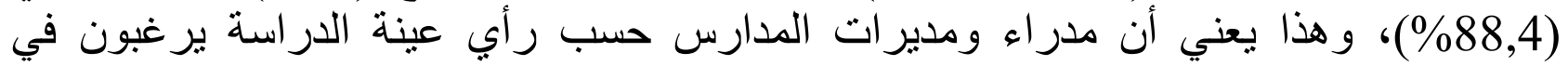

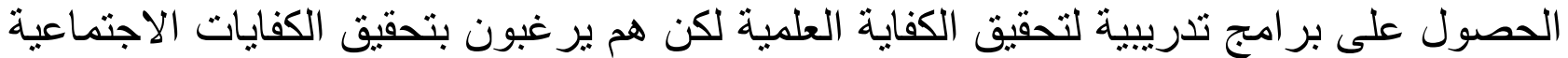

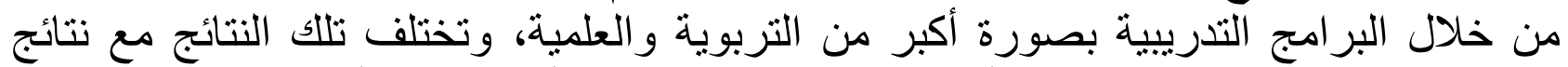

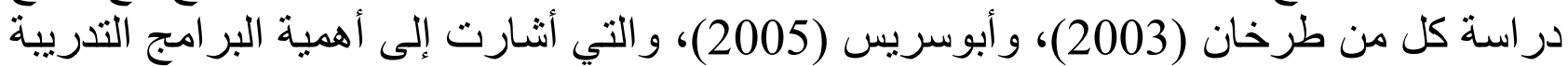

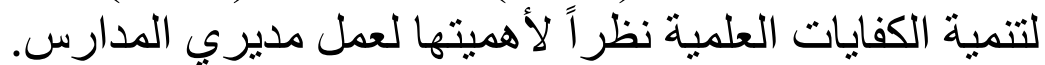

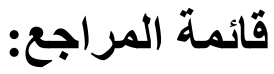

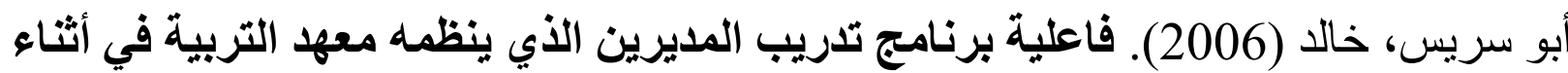

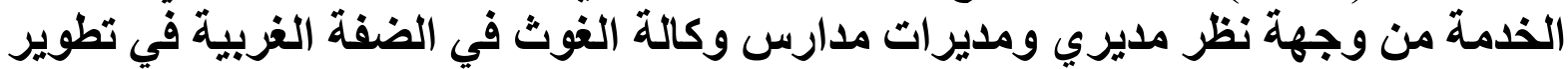

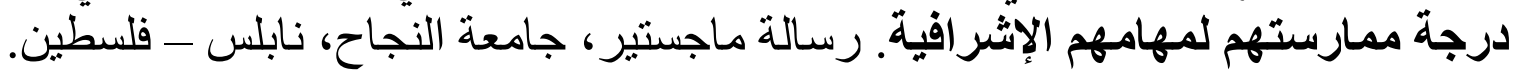

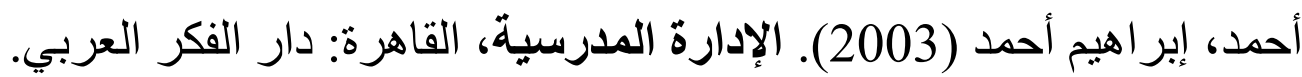

أحمد، إبر اهيم أحمد (2006). رفع كفاعة الإدارة المدرسية. القاهرة: مكتبة المعارف الحديثة.

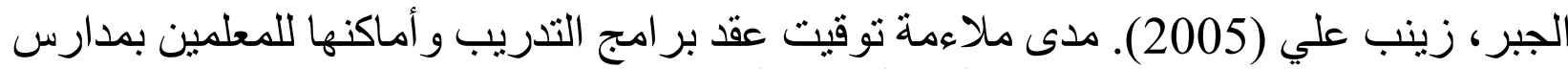

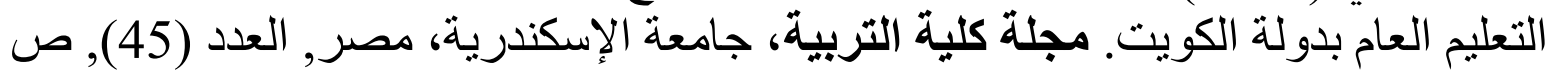
ص ص254-123

حجي، أحمد إسماعيل (1998). الإدارة التعليمية والإدارة المدرسية. القاهرة: دار الفكر العربي.

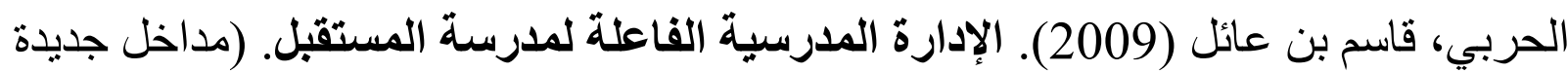

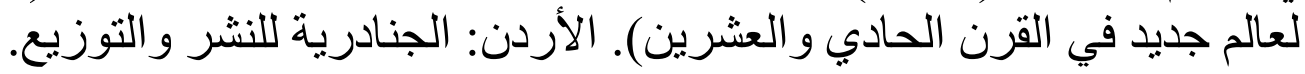

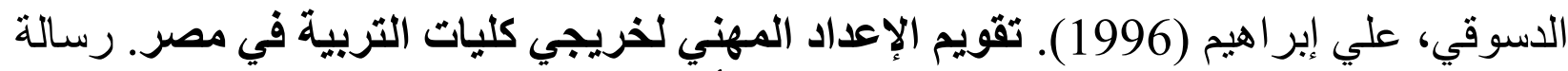

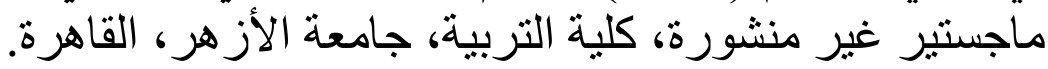

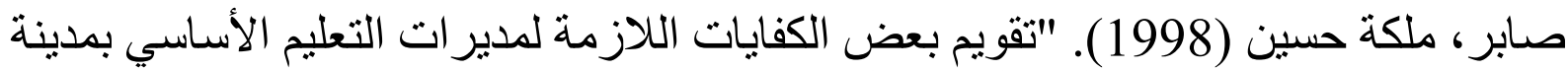

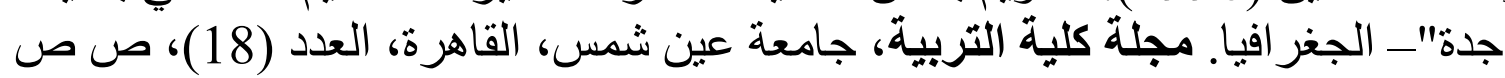
.129-110

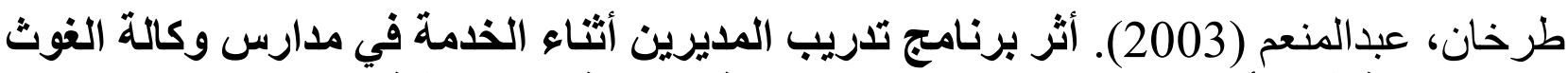

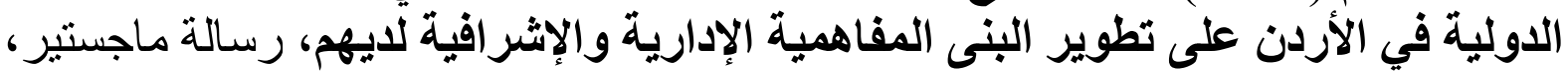

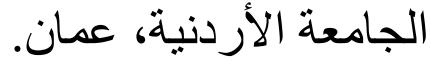

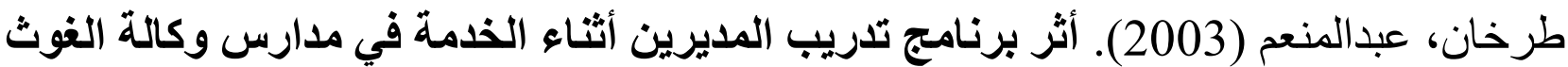

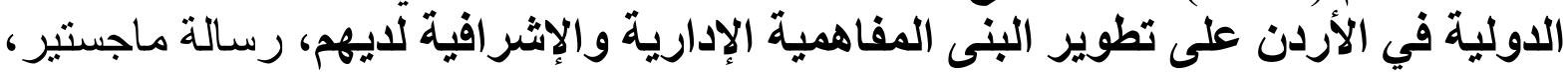




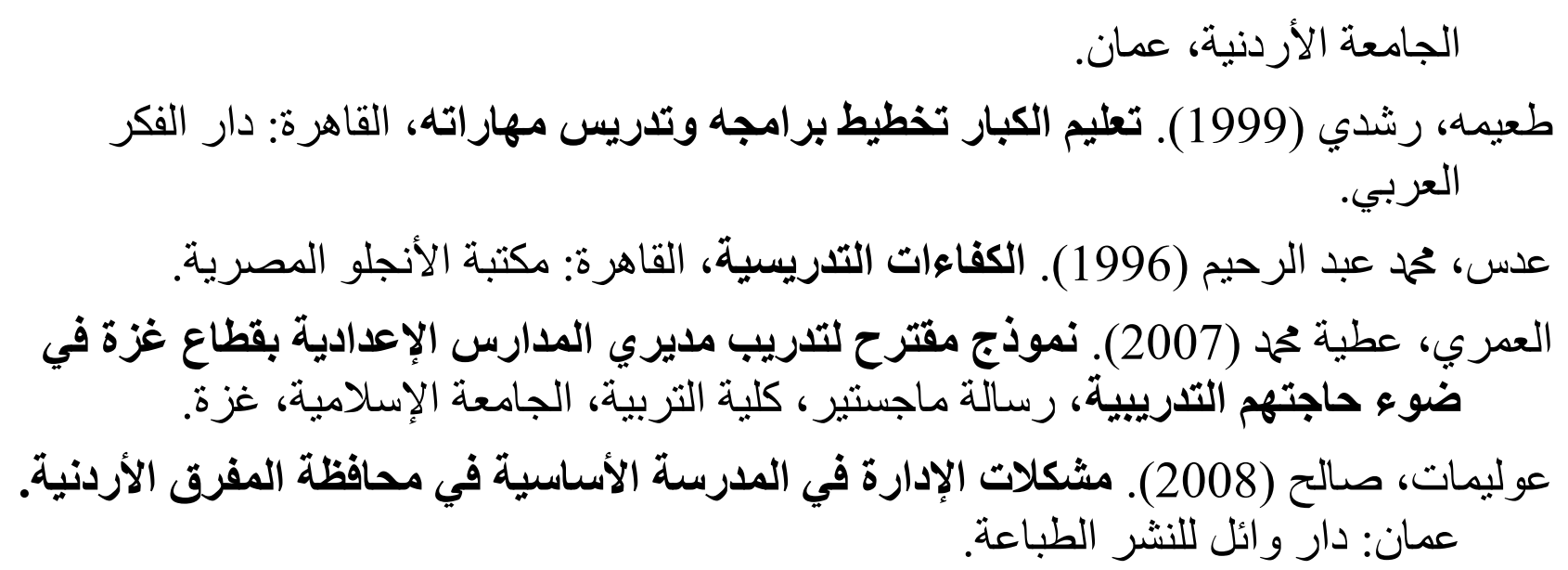

ARABIC REFERENCES IN ROMAN ALPHABET

'Abu Suris, Khalid (2006). Faeiliat Barnamaj Tadrib Almudirin Aldhy Yunazimuh Maehad Altarbiat fi 'Athna' Alkhidmat Min Wijhat Nazar Mudiriin Wamadirat Madaris Wikalat Alghawth fi Aldifat Algharbiat fi Tatwir Darajat Mumarasatihim Limihamihim Al'iishrafiati. Risalat Majstir, Jamieat Alnajahi, Nabulus - Filastin.

'Ahmad, 'librahim 'Ahmad (2003). Al'iidarat Almadarisiatu, Alqahrt: Dar Alfikr Alearabi.

'Ahmad, 'librahim 'Ahmad (2006). Rafae Kafa'at Al'iidarat Almadarasiati. Alqahrt: Maktabat Almaearif Alhadithat.

Aljubr, Zaynab Eali (2005). Madaa Mula'amat Tawqit Eaqd Baramij Altadrib Wa'amakinaha Lilmuealimin Bimadaris Altaelim Aleami Bidawlat Alkuayt. Majalat Kuliyat Altarbiat, Jamieat Al'iiskandriati, Msr, Aleadad (45), S S 123-254.

Hujy, 'Ahmad 'lismaeil (1998). Al'iidarat Altaelimiat Wal'iidarat Almadarasiata. Alqahrt: Dar Alfikr Alearabi.

Alharbi, Qasim Bin Eayil (2009). Al'iidarat Almadrasiat Alfaeilat Limudrisat Almustaqbal. (Mdakhil Jadidat Liealam Jadid fi Alqarn Alhadi Waleishrina). Al'ardin: Aljunadriat Lilnashr Waltawzie.

Aldasuqi, Eali 'librahim (1996). Taqwim Al'iiedad Almahnii Likharijii Kulyat Altarbiat fi Masra. Risalat Majsatayr Ghyr Manshurati, Kuliyat Altarbiat, Jamieat Al'azhari, Alqahirat.

Sabir, Malikat Husayn (1998). "Tqawim Bed Alkifayat Alllazimat Limadirat Altaelim Al'asasii Bimadinat Jd"Aljghrafya. Majalat Kuliyat Altarbiati, Jamieat Eayan Shams, Alqahirat, Aleadad (18), S S 110-129.

Turkhan, Eabdalmnem (2003). 'Athar Barnamaj Tadrib Almudirin 'Athna' Alkhidmat fi Madaris Wikalat Alghawth Alduwaliat fi Al'urduni Ealaa Tatwir Albinaa Almufahimiat Al'iidariat Wal'iishrafiat Ladayhim, Risalat Majstayr, Aljamieat Al'urduniyatu, Eamaan.

Turkhan, Eabdalmnem (2003). 'Athar Barnamaj Tadrib Almudirin 'Athna' Alkhidmat fi Madaris Wikalat Alghawth Alduwaliat fi Al'urduni Ealaa Tatwir Albinaa Almufahimiat Al'iidariat Wal'iishrafiat Ladayhim, Risalat Majstayr, Aljamieat Al'urduniyatu, Eamaan.

Taeimuh, Rashduy (1999). Taelim Alkibar Takhtit Biramijih Watadris Muharatihi, Alqahrt: Dar Alfikr Alearabi.

Eadis, Muhamad Eabd Alrahim (1996). Alkufaa'at Altadrisiatu, Alqahirt: Maktabat Al'anjilu Almisriat.

Aleamri, Eatiat Muhamad (2007). Namudhaj Muqtarah Litadrib Mudiri Almadaris Al'iiedadiat Biqitae Ghazat fi Daw' Hajatihim Altadribiati, Risalat Majstir, Kuliyat Altarbiati, Aljamieat Al'iislamiati, Ghazat.

Eawlimat, Salih (2008). Mushkilat Al'iidarat fi Almadrasat Al'asasiat fi Muhafazat Almafraq Al'urduniati. Eamana: Dar Wayil Lilnashr Altabaeat.

\section{REFERENCES}

Aahlin. U. (2005). Challenges of Educational Changes in Training of the Teacher's Role and Professional Development in Japan and Palestinian Area. M.

Abdeen, Mohamed A. (2001). Study of the actual and Ideal Task behaviors of Arab Private School Principles in Jerusalem. "Ph. D". 
Doglas, W. (2006). School Public Relations Programs in Selected Wisconsin Public School Districts. Dissertation Abstract International, Vol. (55), No. (5) The University of Wisconsin.

Batainch, Ahmed. (1996). The Effect of on Eight Week Mastery Learning Approach Teacher Training Program on Achieving Mastery of the Practice and Reciprocal Styles of Teaching Physical Education. Dissertation Abstracts International, vol.40, No.9.

Rober, N. (2007). Perceived Importance of Competencies Resource, Michigan University.

Smith, J. (1998). The Elements of Lesson Design Elementary Public-School Student's Service Training. Dissertation Abstracts International vol.48, No.3.

Bernard Moswel A. (2006). Teacher Professional Development for New School Improvement Bots Wana International. Journal of Lifelong Education, Vol.25, No.6, pp 112-143.

Chatles, Johnson. (2006). Identifying and Verifying Competencies, Collage of Education University of Georgia.

Dodl, Norman. (2005). The Florida Catalogue of Teacher Competencies Tallahassee Florida. State. 